\title{
Reduction of fire spalling in high-performance concrete by means of superabsorbent polymers and polypropylene fibers
}

\author{
Giovanni P. Terrasi ${ }^{1}$, Pietro Lura ${ }^{1,2}$ \\ ${ }^{1}$ Empa, The Swiss Federal Laboratories for Material Science and Technology, Dübendorf, Switzerland \\ ${ }^{2}$ ETH, Institute for Building Materials, Zurich, Switzerland
}

\begin{abstract}
High-performance concrete (HPC) is prone to explosive spalling when exposed to fire, which may lead to failure of the concrete elements. Polypropylene fibers (PP) are often added to HPC, as upon their melting they create channels through which water vapor is evacuated, preventing the build-up of high vapor pressures. In high-performance self-compacting concrete (HPSCC), the amount of PP fibers needs to be limited in order to keep the self-compacting properties, which may reduce the fire resistance. In this paper, a novel strategy to reduce fire spalling in HPSCC is illustrated, based on adding small particles of superabsorbent polymers (SAP) during mixing. The SAP end up as empty macropores, similar to air voids, in the HPSCC matrix. The PP fibers-SAP voids system percolates at a lower fiber loading than the fibers alone, allowing maintenance of the self-compacting properties while reducing substantially the fire spalling. In particular, in this paper it is shown how addition of SAP is able to reduce fire spalling in thin-walled HPSCC slabs prestressed with carbon fibre reinforced plastic (CFRP) reinforcement. The results of an experimental study on 6 one meter long thin-walled slabs subjected to central precompression by CFRP tendons in a standard fire following ISO 834 are presented.
\end{abstract}

\section{INTRODUCTION}

Sustainability considerations in precast concrete have led to the development of novel thinwalled concrete structural elements through cautious selection, design, and optimization of both the concrete mixtures and of the reinforcing materials. An example are slender structural elements made of high-performance, self-consolidating, fibre-reinforced concrete (HPSCC) reinforced with high-strength, lightweight, and non-corroding prestressed carbon fibre reinforced plastic reinforcement (CFRP) [1]. As for all load-bearing structural members in buildings, the fire performance of these members must be understood to allow their safe use. It is well known that the bond strength between both steel and fibre reinforced plastic (FRP) reinforcing bars and concrete deteriorates at elevated temperature. Moreover, while HPC outperforms conventional concrete in nearly every performance category, one Achilles' heel is its performance when exposed to fire. In particular, HPC is prone to explosive spalling, which decreases the load-carrying capacity and the fire resistance of the concrete elements. The main mechanisms of spalling appears to be pressure build-up of vapour during heating (pore pressure spalling, see e.g. [2]) in the fine pores of the HPC matrix, which cannot be relieved because of its low gas permeability, and different expansion rates between aggregates or reinforcement and mortar (thermal stress spalling). The main factors influencing spalling are [3][4]: heating rate (above $3{ }^{\circ} \mathrm{C} / \mathrm{min}$ ), gas permeability and moisture content (above $2-3 \%$ ). It is moreover known that spalling is enhanced by concrete compression, which explains why prestressed concrete is 
particularly at risk of spalling when service loads are not decompressing the fire-exposed surfaces of a prestressed concrete element. In particular, the spalling behaviour of HPSCC subjected to fire has not been extensively studied and thus remains largely unknown. In its fire resistance chapter, the RILEM TC 205-DSC [5] state-of-the-art report points out the significantly higher spalling tendency for self-compacting concrete (SCC) than for vibrated concrete with the same w/c-ratio and hardening conditions.

A well-known method to release the pressure is embedding organic fibers (especially polypropylene fibers at small diameter $<100 \mu \mathrm{m}$ ) of different lengths into the HPC matrix [5]. The fibers melt and provide channels that allow evacuating the vapour, relieving the internal pressure and avoiding explosive spalling and loss of concrete cross-section in fire. The amount of fibres needed varies and depends on the type and geometry of the fibres, type of concrete, type of aggregates, loading conditions and moisture content. There are several other theories on the working mechanism of PP fibres. A review thereof can be found e.g. in [6]. In particular continuous channels may also be formed at the interfaces between the PP fibres and the concrete matrix due to poor interfacial adhesion and/or a relatively more porous transition zone at the interface. This phenomenon, called Pressure-Induced Tangential Space (PITS) theory [6], is postulated as enhancing concrete moisture migration during heating.

To be efficient, the polypropylene (PP) fibers need to form a percolated network through the whole microstructure of the HPC, so that once molten they are able to evacuate the water vapour and decrease the gas pressure [3]. Alternatively, it may be sufficient that the PP fibers form a percolated network with the regions of high porosity in the concrete, which are concentrated in the interfacial transition zone between the cement paste and the aggregates. In both cases, this implies that a high loading of the fibers in the fresh mixtures is needed. In tests on HPSCC, improved resistance against fire spalling has been observed at about $5 \mathrm{~kg} / \mathrm{m}^{3}$ (or $0.5 \%$ by volume of concrete) of PP fibers [4]. However, this high volume of fibers causes a loss of the self-compacting properties. At lower loadings (typically $2 \mathrm{~kg} / \mathrm{m}^{3}$, or $0.2 \%$ by volume of concrete), the self-compacting properties can be maintained, however the fire spalling resistance is only marginally improved [4].

\subsection{Addition of superabsorbent polymers to reduce fire spalling}

In this study, a novel approach allowed reaching percolation of the fibers in a HPC matrix using a low fiber loading, and thereby maintaining the self-compacting properties of HPSCC. This approach consists in including dry superabsorbent polymer (SAP) particles in the mixture composition of HPSCC [7][8]. Superabsorbent polymers (SAP) have recently found application in concrete technology, thanks to their ability to absorb amounts of water many times their own mass, retain it in the fresh concrete and release it at a later time during cement hydration, which leaves the SAP inclusions as empty pores (ideally about 100-300 $\mu \mathrm{m}$ across) which are uniformly distributed in the HPC matrix [7]. A primary application of SAP has been in internal curing of low water-to-binder ratio concrete, especially to reduce autogenous shrinkage [7].

The novel approach for reducing the spalling of HPC described in this paper consists in creating a system of 100-300 $\mu \mathrm{m}$ diameter voids in the cement paste that are able to bridge the channels created by molten PP fibers in HPSCC subjected to fire and allow their percolation at considerably lower PP fiber loading (e.g. at $2 \mathrm{~kg} / \mathrm{m}^{3}$ instead of $5 \mathrm{~kg} / \mathrm{m}^{3}$ ). This reduces the likelihood of fire spalling and improves the fire resistance of the HPSCC mixtures, without losing the self-compacting properties [8]. 
This paper summarizes and analyzes the main results of an experimental study presented in detail elsewhere [8][9] on 6 small-scale thin-walled slabs subjected to central precompression by CFRP tendons in a standard fire following ISO 834. In particular, an attempt is made to improve the spalling behaviour of a previously studied PP fibre-modified HPSCC [4] by the addition of SAP. The results elucidate the performance of precast CFRP pretensioned HPSCC elements in fire and show the effectiveness of SAP in reducing the spalling tendency of HPSCC.

\section{MATERIALS}

The CFRP prestressing bars used were round, pultruded, quartz sand-coated CFRP tendons with a diameter of $5.4 \mathrm{~mm}$ (specimens 1, 2, 3 and 4) and of $4.2 \mathrm{~mm}$ (specimens 5 and 6). The carbon fibres in the bars were Tenax UTS at a fiber volume fraction of approximately $64 \%$; the resin was Bakelite 4434 epoxy. The tendons' design tensile strength and elastic modulus were 2,000 $\mathrm{MPa}$ and $150 \mathrm{GPa}$, respectively. Tendon properties can be found in [4]. The quartz-sand coating (average grain size $0.5 \mathrm{~mm}$ ) was bonded in-line after the pultrusion using the same epoxy resin in order promote a strong bond. Because of the known susceptibility of the FRP-to-concrete bond to elevated temperature exposure [4], the influence of fire on the bond properties of a CFRP-pretensioned element was of particular interest in the current tests.

The CFRP tendons considered herein were pultruded using an epoxy resin matrix with a relatively high glass transition temperature, $\mathrm{T}_{\mathrm{g}, \mathrm{DMA}}=121^{\circ} \mathrm{C}$ [4], in an effort to enhance their resistance to elevated service temperatures. The $\mathrm{T}_{\mathrm{g}}$ of a polymer resin is widely used to define the limiting service temperature at which degradation of the tensile and bond strength of composites materials becomes unacceptable.

The current study focussed on two specific high performance concrete (HPC) mixtures, both of strength class C75/90. The two concrete mixtures are denoted as "Ref" and "SAP", and their mixture designs are given in Table 1 . These HPCs are characterized by a precise grain size distribution of 0-8 mm limestone aggregates. The amount of cement (CEM II/A-D 52.5R, which includes $20 \%$ of silica fume) is $464-488 \mathrm{~kg} / \mathrm{m}^{3}$. Fly ash and high performance superplasticizers (SP) play a key role in the mixture design of the HPC, which showed optimum self-compacting properties at $\mathrm{w} / \mathrm{b}$ 0.312. Short PP microfibers at a dosage of $2 \mathrm{~kg} / \mathrm{m}^{3}$ were used to prevent plastic shrinkage cracking and to increase the concretes' resistance against spalling in fire.

Table 1. Mixture proportioning and slump flow of the two high performance concretes

\begin{tabular}{llll}
\hline Concrete type (name) & & Ref & SAP \\
\hline Cement CEM II/A-D 52.5R & {$\left[\mathrm{kg} / \mathrm{m}^{3}\right]$} & 488 & 464 \\
Fly ash & {$\left[\mathrm{kg} / \mathrm{m}^{3}\right]$} & 122 & 116 \\
Limestone aggregate $0-8 \mathrm{~mm}$ & {$\left[\mathrm{~kg} / \mathrm{m}^{3}\right]$} & 1582 & 1582 \\
SP in \% of binder & {$[\%]$} & 1.4 & 2.5 \\
PP microfibers & {$\left[\mathrm{kg} / \mathrm{m}^{3}\right]$} & 2 & 2 \\
Superabsorbent polymer & {$\left[\mathrm{kg} / \mathrm{m}^{3}\right]$} & - & 1.93 \\
Total w/b (including water in the SAP) & {$[-]$} & 0.312 & 0.34 \\
Basic w/b (excluding water in SAP) & {$[-]$} & 0.312 & 0.286 \\
Slump flow of HPSCC after prEN 12350-8 & {$[\mathrm{mm}]$} & $700-800$ & $700-720$ \\
\hline
\end{tabular}


The PP microfibers were Vulkan Harex Polycon HPC 20, with a length of $20 \mathrm{~mm}$ and rectangular fibre cross section (width of $200 \mu \mathrm{m}$, thickness of $37 \mu \mathrm{m}, \mathrm{T}_{\text {melting }}=170^{\circ} \mathrm{C}$ ).

Solution-polymerized SAP with irregular particles of size $63-125 \mu \mathrm{m}$ were used. Based on the results of previous studies, the water absorption was about $16 \mathrm{~g} / \mathrm{g}$ [10]. The SAP were added dry in an amount of $0.33 \%$ by cement weight. During mixing, they absorb part of the mixing water and form water-filled inclusions which are about 2.5 times larger than the original particles [10]. Taking into account this rapid absorption, the basic $w / b$ of the HPC with SAP addition is reduced to 0.286 , which explains the higher dosage of superplasticizer required $(2.5 \%$ instead of $1.4 \%)$. In addition, the presence of the swollen SAP in the matrix also influences the workability. One should also consider that the addition of SAP affects the mechanical strength properties of the concrete [8]: The reference concrete showed about $12 \%$ higher compressive strengths (mean value $110 \mathrm{MPa}$ ) than the same concrete with SAP addition at age 91 days (mean value $96 \mathrm{MPa}$ ), which is not surprising if one considers the higher porosity of the SAP mixture. Curing of the test specimens consisted in keeping the slabs under a polyethylene foil for 3 days, after which prestress release took place. The specimens were then kept for one week at $90 \% \mathrm{RH}$, followed by storage for $6-8$ months in a $20^{\circ} \mathrm{C}, 70 \% \mathrm{RH}$ chamber before fire testing. The moisture content of the reference mixture was measured in a previous study [4]. Moisture contents between 3.8\% and 4.4\% at ages higher than 3 months under similar storage conditions were measured. It is remarked that moisture contents above above $2-3 \%$ are considered a risk factor for fire spalling [3].

\section{TEST SPECIMENS}

The HPSCC slab (plate) specimens' geometry was $45 \mathrm{~mm}$ thickness (giving a CFRP cover of 20 $\mathrm{mm}) \times 175 \mathrm{~mm}$ width (Fig. 1) $\times 1080 \mathrm{~mm}$ length. Two HPSCC types, Ref and SAP, were used, with $2 \mathrm{~kg} / \mathrm{m}^{3}$ short PP-fibres (see section 2 and Table 1). The slabs showed a central camber of 2-3 mm, caused by the central prestress through four CFRP tendons. The tendons' prestress at release was between 1'000 and 1'200 MPa/tendon and the prestress losses at the time of testing are estimated at $10 \%$ of the initial prestress. Unfortunately one tendon anchorage failed before prestress release for slabs 1 Ref and 2_Ref, causing a prestress reduction to $75 \%$ of the planned value of $110 \mathrm{kN}$. Curing of the specimens and release of the tendons is described in section 2 . No visible shrinkage cracks $(\mathrm{w}>0.01 \mathrm{~mm})$ were observed on the slabs' surfaces. The specimens' data are summarised in Table 2.

Table 2. Test specimens data and main results of the fire tests. Initial CFRP prestress is indicated.

\begin{tabular}{|c|c|c|c|c|c|c|c|}
\hline $\begin{array}{l}\text { Spec. } \\
\text { name }\end{array}$ & $\begin{array}{l}\text { Age } \\
{[\mathrm{mts}]}\end{array}$ & $\begin{array}{l}\text { CFRP-tendon } \\
\text { diameter }\end{array}$ & $\begin{array}{l}\text { CFRP } \\
\text { prestress } \\
{[\mathrm{kN}]} \\
\end{array}$ & $\begin{array}{l}\text { Cover } \\
{[\mathrm{mm}]}\end{array}$ & $\begin{array}{l}\text { Thick- } \\
\text { ness } \\
{[\mathrm{mm}]}\end{array}$ & $\begin{array}{l}\text { Time of } \\
\text { first/second } \\
\text { spalling }\end{array}$ & Remarks \\
\hline 1_Ref & 8 & $5.4 \mathrm{~mm}$ & 82.4 & 20 & 45 & $18^{\prime} / 19^{\prime} 55$ & Longitudinal cracks after $25^{\prime}$ \\
\hline 2_Ref & 8 & $5.4 \mathrm{~mm}$ & 82.4 & 20 & 45 & $15^{\prime}$ & $\begin{array}{l}\text { Small spall at midspan } \\
\text { (longitudinal cracks after } 25^{\prime} \text { ) }\end{array}$ \\
\hline 3_SAP & 8 & $5.4 \mathrm{~mm}$ & 91.6 & 20 & 45 & None & Longitudinal cracks after $41^{\prime}$ \\
\hline 4_SAP & 8 & $5.4 \mathrm{~mm}$ & 91.6 & 20 & 45 & None & Longitudinal cracks after 51 ' \\
\hline 5_SAP & 6 & $4.2 \mathrm{~mm}$ & 66.5 & 20 & 45 & None & No cracks \\
\hline 6 SAP & 6 & $4.2 \mathrm{~mm}$ & 66.5 & 20 & 45 & None & 1 longitudinal crack after 90 ' \\
\hline
\end{tabular}


SMAR 2015 - Third Conference on Smart Monitoring,

Assessment and Rehabilitation of Civil Structures

SIMAR 2015

\section{FIRE TESTS}

In order to gain insight on the performance and spalling resistance of thin-walled CFRP prestressed HPC elements with and without SAP in case of exposure to fire, 3 small scale fire tests were performed with two prestressed slabs per test in Empa's fire laboratory using Empa's small horizontal furnace (Fig. 1) [8]. The objectives of these fire tests (following the ISO 834 standard) were:

- to measure the spalling time, the failure time and mode for a CFRP-prestressed HPSCC slab with cover $20 \mathrm{~mm}$ under central prestress without additional external load; and

- to measure the resulting deflections of the prestressed slabs in fire: The two slab specimens were instrumented with 3 LVDTs (range $500 \mathrm{~mm}$, accuracy $0.05 \mathrm{~mm}$ ) each at $1 / 4,1 / 2$, and $3 / 4$ of their span.

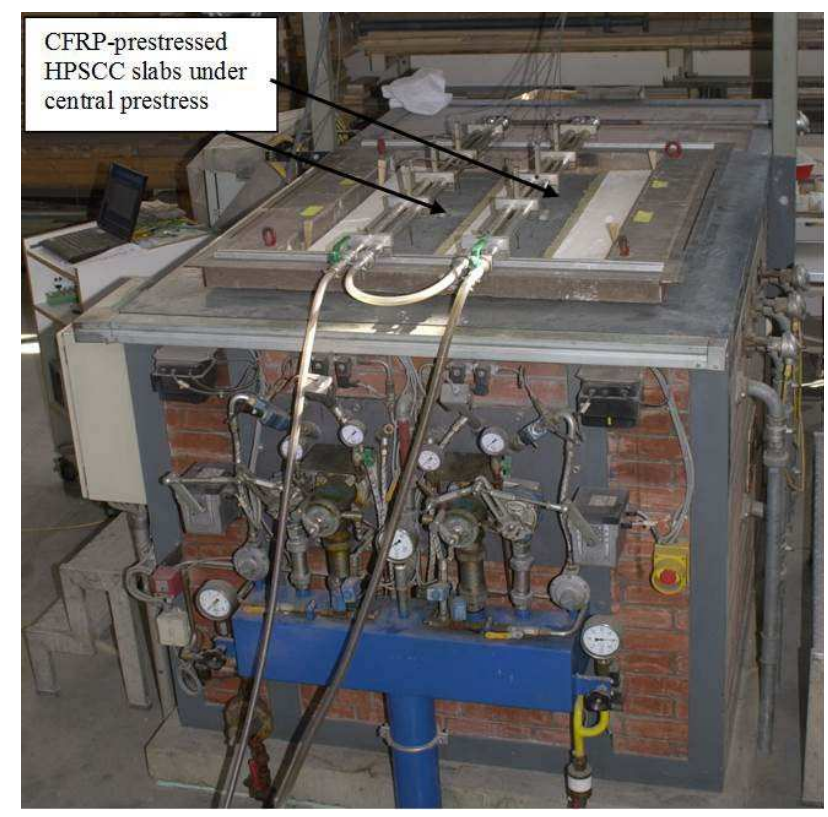

Figure 1. Empa's horizontal furnace for the small scale fire tests on two CFRP-prestressed HPC slabs.

The test span of the simply-supported slabs was $1020 \mathrm{~mm}$ (Empa's small horizontal furnace has a length of $1000 \mathrm{~mm}$ ). The slabs had therefore only $30 \mathrm{~mm}$ of (cold) overhang per side. A central prestress loading condition was selected with prestress levels given in Table 2. The prestress was introduced by 3 (specimens 1_Ref and 2_Ref), respectively 4 CFRP tendons located at the mid-plane of the specimens (Fig. 2). It is noteworthy that the central precompression is a more severe testing condition (with respect to spalling) than an additional bending load on the slabs, which would have the effect of decompressing their central span (see section 1 , Introduction).

The fire test condition chosen was an ISO 834 fire, considered to represent a realistic scenario for a façade element (a typical application of the thin-walled CFRP prestressed HPC slabs studied [1]), producing a furnace temperature of e.g. about $840^{\circ} \mathrm{C}$ after 30 minutes. It was decided to expose to fire the plates' smooth surfaces that had been cast in contact with the moulds. In fact, smooth surfaces would give a similar heat transfer condition for all the specimens, while surfaces with different roughness and surface-near compaction degree might result in differences in heat transfer and thermal load between the specimens. 

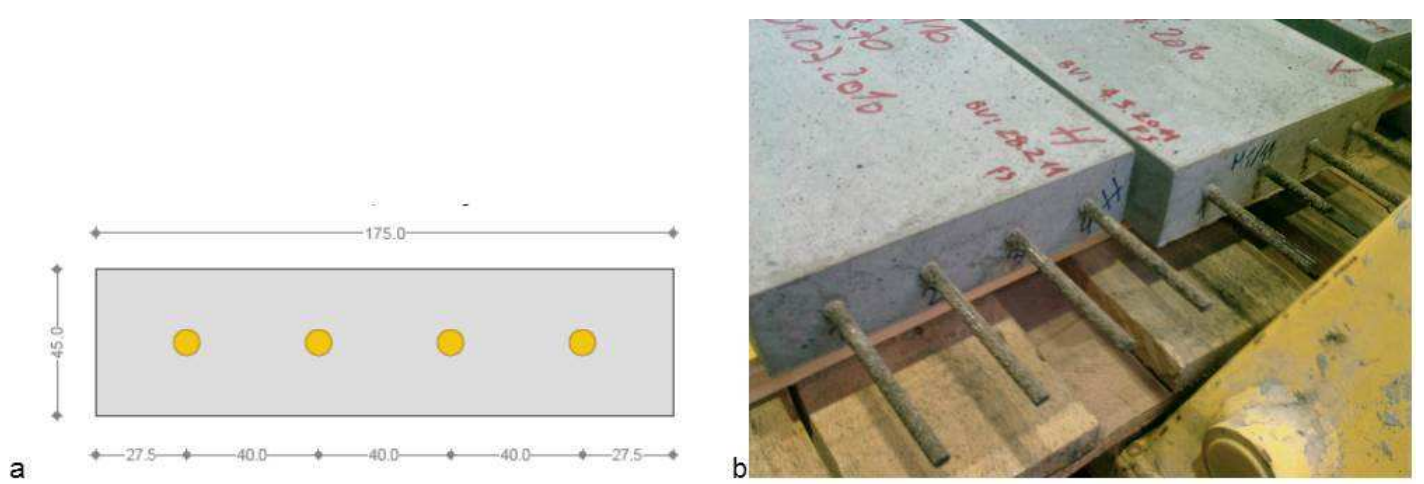

Figure 2. a) Scheme of cross section of CFRP-prestressed, HPSCC slab subjected to fire tests and b) specimens 1_Ref and 2_Ref before testing.

\section{RESULTS AND DISCUSSION}

The main results of the three fire tests are summarized in Table 2. All specimens resisted 90 minutes of the ISO 834 fire test without collapse. However, all specimens, with the exception of 5_SAP, showed longitudinal cracks directly under and above the CFRP tendons that developed during exposition to the high temperatures. First cracking was observed after 25 minutes, with a furnace temperature of approximately $815^{\circ} \mathrm{C}$.

With regard to the main objective of the tests - the investigation of the spalling behaviour of the two different prestressed HPSCC in a fire scenario - Table 2 clearly shows the superior spalling resistance of the SAP-modified HPSCC type. Specimens 3_SAP, 4_SAP, 5_SAP and 6_SAP did not show any concrete spalling, while specimens 1_Ref and 2_Ref showed first concrete spalls on the fire-exposed surface after 18 minutes and 15 minutes, respectively. The second spalled area of specimens 1_Ref is exemplarily shown in Fig. 3.

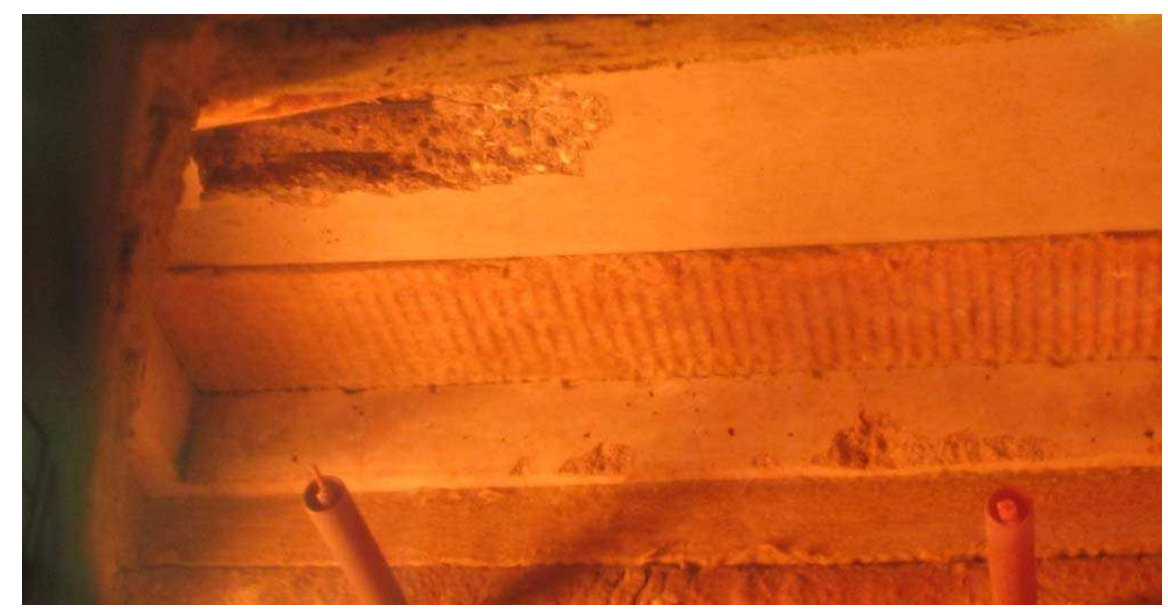

Figure 3. Second spall of specimen 1_Ref near southern support (after about 20 minutes in the fire).

The steady increase of the $1 / 4$-span and central deflection of the slabs during the fire test is exemplarily shown in Figure 4 for the first fire test (specimens 1_Ref and 3_SAP, see Table 2). The increase in deflection, due to a combination of thermal bowing, loss of flexural stiffness, and bond reductions leading to tendon slippage, was gradual and very similar in terms of deflection slope development to what was observed in [4]. 


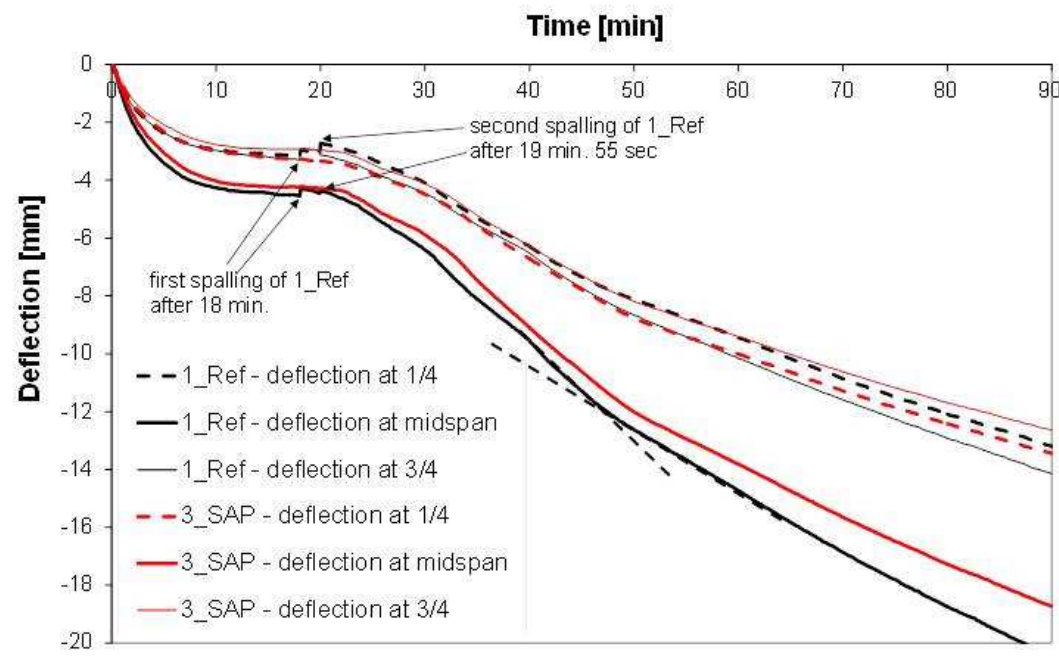

Figure 4. Deflection vs. time curves of specimens 1_Ref and 3_SAP during the first fire test.

The simply-supported slabs showed a reasonable deformation capacity, with measured midspan deflection values corresponding to $\operatorname{span} / 50(\approx 20 \mathrm{~mm})$ after 90 minutes in the fire. First and second spalling of the fire-exposed surface of specimen 1_Ref are clearly denoted by two kinks in the 1/4-point and midspan deflection vs. time curves after 18 and 20 minutes, caused by the small local explosion producing the flakes of concrete that are suddenly broken off the specimen.

The deflection increase in the later stages of the fire test (note the slope variation after ca. 45 minutes) is believed to be influenced by the loss of prestress caused by bond degradation between the CFRP tendon and the concrete. A measurement of the tendons' end slippage vs. time would be necessary to confirm this hypothesis. At the end of testing, tendon slippages (draw-in) ranging between $2 \mathrm{~mm}$ and $8 \mathrm{~mm}$ were measured by a micrometer at the slabs' end faces. The sum of the two end slippages of each single tendon after testing was always in the range of the total prestress elongation (8 $\mathrm{mm}$ for specimens 1_Ref, 2_Ref, 5_SAP and 6_SAP, and $6.5 \mathrm{~mm}$ for specimens 3_SAP and 4_SAP), showing that the complete prestess was lost during the fire test.

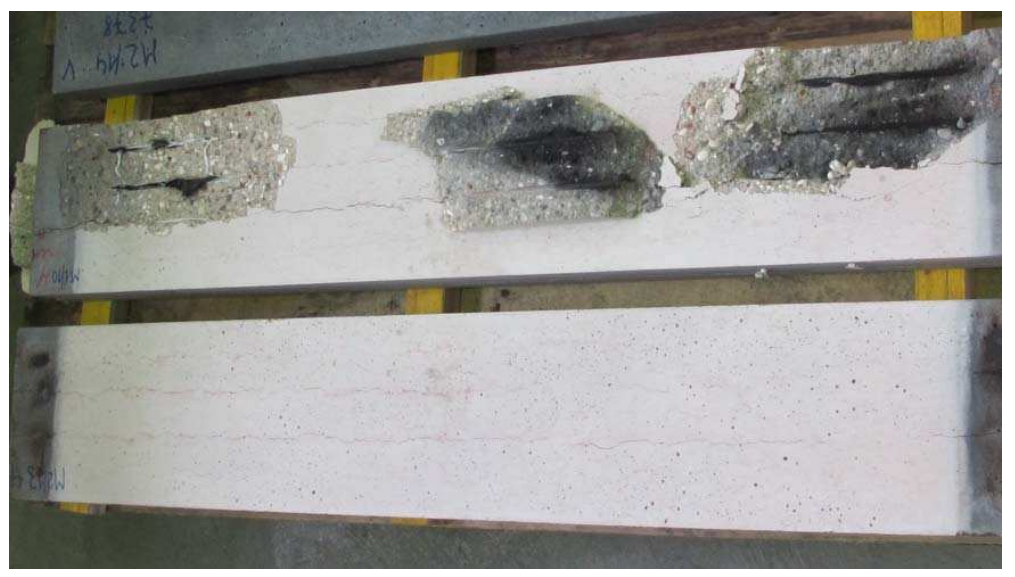

Figure 5. Fire exposed surface of specimen 1_Ref after 90 minutes in the fire denoting 3 spalled areas (above), next to specimen 3_SAP without spalling (below, tested in the same fire experiment as 1_Ref). 
During the fire tests, the development of several longitudinal cracks was observed for 5 of the 6 specimens. The time of first cracking is given in Table 2. After the end of testing, several longitudinal splitting cracks running along all four CFRP tendons were observed over the slabs' fire-exposed surfaces (Figure 5) and, to a lesser extent, on their top surfaces. These splitting cracks were probably caused by thermal incompatibility of the orthotropic CFRP tendon with the HPC combined with thermal and mechanical stresses in the prestress transfer and support area. At temperatures between $10-100^{\circ} \mathrm{C}$, the coefficient of thermal expansion of the CFRP tendons transverse to the fibre direction is about 2.7-times higher than that of concrete [4]. The mismatch in thermal expansion induces tangential stresses and finally splitting cracks in the concrete cover. These cracks eased the slippage of the tendons during the loss of bond. Despite this, the CFRP tendons were still able to keep the slabs in one piece after 90' of fire exposure.

\section{CONCLUSIONS}

In this study, a positive effect of SAP on the spalling resistance of HPSCC was demonstrated. Out of 4 specimens with SAP, none showed fire spalling, while both reference samples without SAP did. It is supposed that the mechanisms by which the SAP act in HPSCC exposed to high temperatures is bridging the PP fibers and allowing their percolation already at a low volume content $(0.2 \%$ by volume of concrete), when the PP fibers are not percolated either with each other or with the interfacial zone surrounding the aggregates. Combining the SAP with a low amount of PP fibers is beneficial for the fresh properties of the HPSCC, since at the high PP fiber loading needed for percolation (about $0.5 \%$ by volume of concrete), the HPSCC loses its self-compacting properties. An important note is that these promising preliminary results have been obtained with the small furnace at Empa. The size-effect needs to be investigated by upscaling to full-scale slabs $(3.6 \mathrm{~m} \times 200 \mathrm{~mm})$ tested with full scale fire tests in a larger furnace [4].

\section{References}

[1] Terrasi, G.P. (2013). Prefabricated thin-walled structural elements made from high performance concrete prestressed with CFRP wires. Journal of Material Science Research 2(1) 14 S.-976.

[2] Mindeguia, J. C., Pimienta, P., Noumowé, A., Kanema, M. (2010). Temperature, pore pressure and mass variation of concrete subjected to high temperature. Cement and concrete research 40(3), 477-487.

[3] Khoury, G.A. (2000) Effect of fire on concrete and concrete structures. Progress in Structural Engineering and Materials 2(4), 429-447.

[4] Terrasi, G.P., Bisby, L., Barbezat, M., Affolter, C., Hugi, E. (2012). Fire Behavior of Thin CFRP Pretensioned High Strength Concrete Slabs. Journal of Composites for Construction 16(4), 381-394.

[5] Rilem TC 205-DSC (2007). RILEM Report 38: Durability of Self-Compacting Concrete-State-of-theArt Report of RILEM Technical Committee 205-DSC, Geert De Schutter \& Katrien Audenaert Eds.

[6] Khoury G.A. Polypropylene Fibres in Heated Concrete - Part 2: Pressure Relief Mechanisms and Modelling Criteria. Magazine of Concrete Research, 2008, 60 (3), 189-204.

[7] Jensen, O.M., Lura, P (2006). Techniques for internal water curing of concrete. Mat.\&Struct. 39, 817

[8] Lura P. and Terrasi G.P., Cement \& Concrete Composites 49 (2014), 36-42.

[9] Lura, P., Terrasi, G.P (2012). Fire resistant concrete. PCT patent application, Dec. 2012.

[10] Trtik, P., Muench, B., Weiss, W.J., Herth, G., Kaestner, A., Lehmann, E., Lura , P. (2010). Neutron tomography investigation of water release from superabsorbent polymers in cement paste. Proc. Int. RILEM Conf. on Material Science (MatSci), September 6-10, 2010, Aachen, DE, PRO 77, 175-185. 